\title{
New Simulation Method of Flashover Rate by Connection of EMTP and MATLAB
}

\author{
Hun-Chul Seo *, Joon-Han**, Sun-Kyu Choi***, Byung-Sung Lee*** \\ and Chul-Hwan Kim ${ }^{\dagger}$
}

\begin{abstract}
Because of the random characteristics of lightning, the Monte Carlo method is applied to estimate the flashover rate due to lightning, however, the simulations using previous methods are difficult to both beginner and expert in power corporations. Therefore, this paper proposes the new and easy method to simulate the flashover rate by connection of electromagnetic transients program (EMTP) and MATLAB. The magnitude of a lightning strike is based on a curve measured in the field, while the classification of direct and indirect lightning depends on the striking distance. In a Korean distribution system, the flashover rate induced by lightning is simulated using proposed method. Simulations of the footing resistance according to the existence of an overhead ground wire (OHGW) are performed and the simulation results are discussed. The simulation results are compared with findings obtained with the IEEE Flash 2.0 program.
\end{abstract}

Keywords: Distribution system, EMTP, Flashover rate, Lightning, MATLAB

\section{Introduction}

Flashovers may occur on distribution lines due to both direct lightning strikes and the voltage induced from nearby strikes. Direct lightning strikes often cause insulation flashover in distribution lines. Lightninginduced voltages are currently a major concern in terms of electromagnetic compatibility and power quality due to the widespread use of sensitive devices connected to distribution lines [1-8]. Therefore, the calculation of flashover rate at specific distribution system configuration is very important for lightning protection. In [8], the indirect lightning performance in overhead lines was assessed using computer code called lightning-induced overvoltage code (LIOV). The assessment of flashover rate using this program is difficult to both beginner and expert in power corporations. The IEEE PES Lightning Performance of Overhead Lines Working Group developed the IEEE Flash 2.0 program to estimate the lightning flashover rates in overhead electric power transmission and distribution lines based on IEEE Stds. 1243 and 1410 [911]. This program can be applied to specific distribution system configuration.

Therefore, this paper proposes the new method to simulate the flashover rate by connection of electro-

$\dagger \quad$ Corresponding Author: College of Information and Communication Engineering, Sungkyunkwan University, Korea. (hmwkim@ hanmail.net)

* School of IT Engineering, Yonam Institue of Digital Technolgy, Korea (hunchul12@yc.ac.kr)

** College of Information and Communication Engineering, Sungkyunkwan University, Korea. (j3angh@gmail.com)

*** Power System Laboratory, KEPRI, Korea (skchoi@kepco.co.kr, leebs@kepri.re.kr)

Received: February 10, 2015; Accepted: January 15, 2016 magnetic transients program (EMTP) and MATLAB. The main role of EMTP is the calculation of lightning overvoltage and the one of MATLAB is the calculation of flashover rate using results of EMTP. Two programs are carried out simultaneously. This method is applied to calculate the flashover rate according to the various configuration of lightning protection system in Korean distribution system

\section{New Simulation Method of Flashover Rate}

Lightning has random characteristics, i.e., the magnitude and location of each lightning strike is different. Therefore, the Monte Carlo method is applied to calculate the flashover rate by lightning. To perform simulations based on the Monte Carlo method, this paper proposes the new simulation method using both EMTP and MATLAB. The concept for the interface between EMTP and MATLAB is shown in Fig. 1. The user must perform the modelling of EMTP and MATLAB, respectively. In EMTP, system configuration, the magnitude of a lightning strike, and the lightning location is modelled. In MATLAB, the m-file coding is required to calculate the flashover rate through the connection of EMTP and MATLAB. After modelling, the simulation is only performed by running in $\mathrm{m}$-file of MATLAB.

\subsection{Role of EMTP}

EMTP first determines the magnitude of a lightning strike and the lightning location. It then calculates the induced voltage in the phase conductor by direct or indirect 


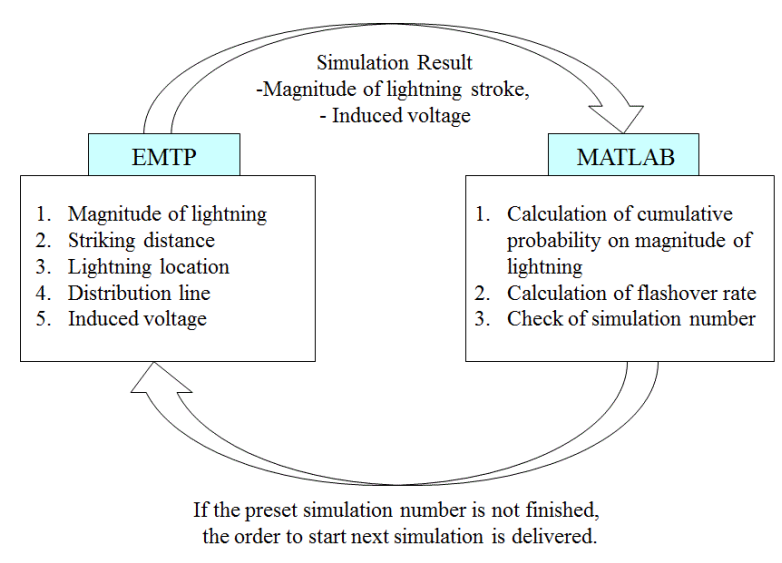

Fig. 1 Interface between the EMTP and MATLAB

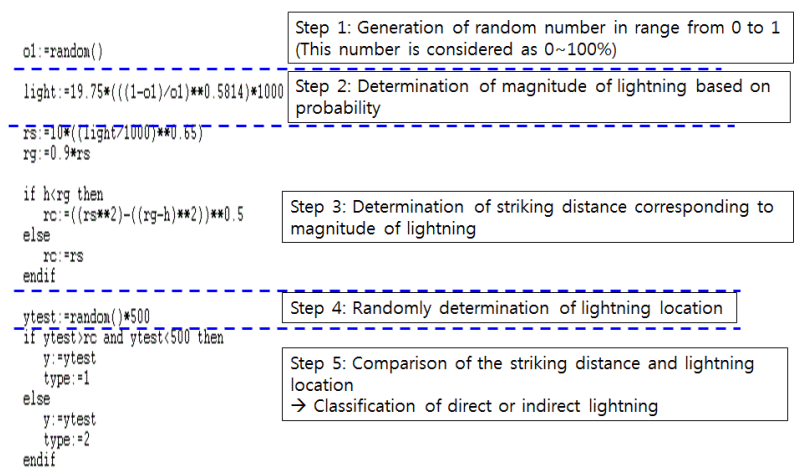

Fig. 2 EMTP/MODELS for determining the magnitude of lightning, lightning location, and striking distance

lightning based on the striking distance. The magnitude of a lightning strike, the lightning location, and the striking distance are evaluated with EMTP/MODELS. Some of the EMTP/MODELS for this procedure are presented in Fig. 2.

\subsubsection{Magnitude of lightning strikes}

In Fig. 2, step 1 and 2 is based on cumulative probability function for lightning strikes as measured by the KEPCO Lightning Detection \& Information Network (KLDNet) of the Korea Electrical Power Research Institute from 2005 to 2010. The cumulative probability distribution versus the lightning strike magnitude is shown in Fig. 3 [12]. The cumulative probability from the KEPRI data is estimated between the Anderson-Erikson and Popolansky methods. The magnitude of a lightning strike in Fig. 3 can be written as

$$
P=\frac{1}{1+\left(\frac{I_{\text {light }}}{19.75}\right)^{1.72}}
$$

where $P$ is the cumulative probability function and $I_{\text {light }}$ is the magnitude of a lightning strike [12].

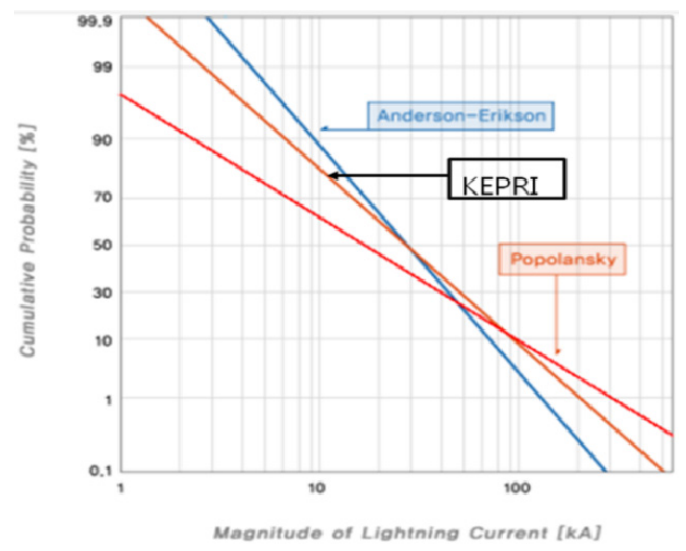

Fig. 3 Cumulative probability distribution versus the lightning strike magnitude

Table 1. Comparison between the simulation results and the field measurements

\begin{tabular}{c|c|c}
\hline $\begin{array}{c}\text { Magnitude of } \\
\text { lightning (kA) }\end{array}$ & $\begin{array}{c}\text { Field Measurements } \\
(\%)\end{array}$ & $\begin{array}{c}\text { Simulation Results } \\
(\%)\end{array}$ \\
\hline 4.4 & 97.4 & 97.4 \\
\hline 10 & 78.4 & 79.4 \\
\hline 20 & 33.4 & 34.8 \\
\hline 30 & 13.6 & 13.6 \\
\hline 50 & 3.5 & 3.6 \\
\hline 100 & 0.6 & 0.8 \\
\hline
\end{tabular}

To validate the accuracy of the modeling, agreement between the simulation results and the field measurements of the cumulative probability of the magnitude of lightning is verified. A comparison of the results when the simulation number is 1000 is shown in Table 1; very good agreement is observed.

\subsubsection{Classification of direct and indirect lightning}

Step 3, 4, and 5 is based on IEEE std. 1410 [9]. The location of a lightning strike, i.e., the distance from the distribution line, is randomly determined in $1 \mathrm{~km}^{2}$ of the distribution line for each lightning event. To distinguish between direct lightning and indirect lightning, the striking distance $y_{\min }$ is determined by IEEE std. 1410 [9]. If the lightning location is less than $y_{\min }$, the direct lightning is considered. If the lightning location is larger than $y_{\text {min }}$, the indirect lightning is considered.

\subsubsection{Modeling of Direct and Indirect Lightning}

The waveform of direct lightning is modeled by EMTP/MODELS based on a Heidler-type analytical formulation [13]. The magnitude of a lightning strike is determined by (10). The modeled waveform is $2 / 70 \mu$ s and it is connected to an overhead ground wire or phase conductor by a type 60 TACS source in EMTP [14-16]. In the case of direct lightning, a pole surge impedance of 200 $\Omega$ is added [5]. 


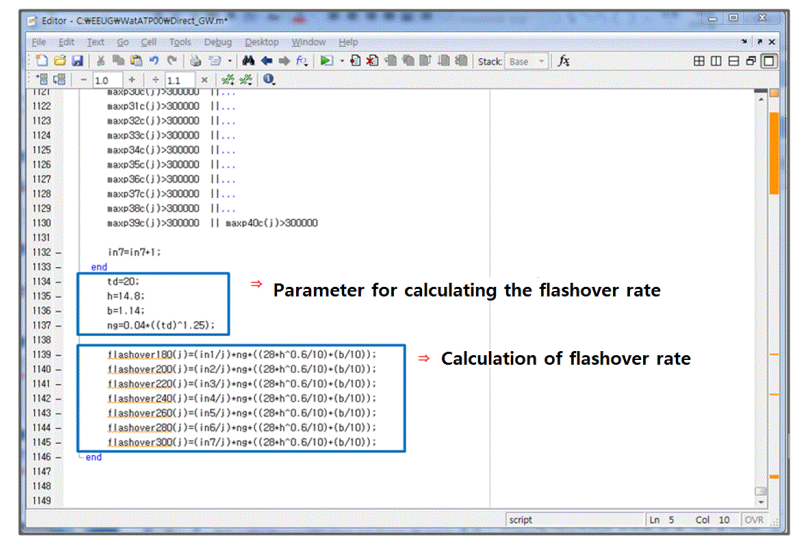

Fig. 4 Part of MATLAB m-file

Many researchers have studied the overvoltage due to indirect lightning [4-5, 17-20]. In this paper, the lightninginduced voltage on an overhead line is calculated via a method proposed by H. K. Hoidalen [17]. This method was implemented in EMTP/MODELS.

\subsection{Role of MATLAB}

After running one EMTP simulation, the magnitude and induced voltage are inputted into MATLAB. P142mat.exe file is necessary in this process. MATLAB calculates both the flashover rate and the cumulative probability of the magnitude of lightning. The flashover rate is calculated by equations in [9]. It then checks the simulation number. If the present simulation number is not the preset simulation number, the signal for the next simulation is delivered to the EMTP. The link between two programs is possible because the EMTP is performed in a disk operating system (DOS) environment using EMTP code written as text, while MATLAB provides the simulating function in the DOS environment. Fig. 4 is part of MATLAB m-fle. After finalizing the simulation, we can find the simulation result in workspace of MATLAB.

\subsection{Comparison with previous methods}

To highlight the proposed method, the advantages and disadvantages of previous and proposed methods are compared as shown in Table 2. The proposed simulation method can consider the various system configurations such as the existence, installation spacing, and grounding resistance of lightning arrester, however, IEEE Flash 2 method can't consider them. Also, the proposed simulation method can use arbitrary cumulative probability function for lightning strikes and randomly set the lightning strike location, however, IEEE Flash 2 method is impossible. IEEE Flash 2 can only use the cumulative probability of a lightning strike median value with $31 \mathrm{kA}$. The proposed methods requires a lot of time to calculate the flashover rate. The time taken for calculation with 500 simulation
Table 2. Comparison of the proposed and previous method

\begin{tabular}{|c|c|c|}
\hline Method Item & Advantages & Disadvantages \\
\hline $\begin{array}{c}\text { IEEE } \\
\text { Flash } 2.0 \\
\text { [7-9] }\end{array}$ & It has short calculation time. & $\begin{array}{l}\text { 1) It can't consider the } \\
\text { existence of lightning } \\
\text { arrester. } \\
\text { 2) It can use only specified } \\
\text { cumulative probability } \\
\text { function for lightning } \\
\text { strikes. } \\
\text { 3) It can't change the } \\
\text { configuration of system. }\end{array}$ \\
\hline $\begin{array}{c}\text { LIOV- } \\
\text { EMTP [6] }\end{array}$ & $\begin{array}{l}\text { It is latest skill to calculate } \\
\text { the flashover rate. }\end{array}$ & $\begin{array}{c}\text { It has a difficulty of use by } \\
\text { closed source. }\end{array}$ \\
\hline $\begin{array}{l}\text { Proposed } \\
\text { method }\end{array}$ & $\begin{array}{l}\text { 1) It can change the } \\
\text { configuration of system. } \\
\text { 2) It can use arbitrary } \\
\text { cumulative probability } \\
\text { function for lightning } \\
\text { strikes. } \\
\text { 3) It can randomly set the } \\
\text { lightning strike location }\end{array}$ & $\begin{array}{l}\text { It requires a lot of time to } \\
\text { calculate the flashover rate. }\end{array}$ \\
\hline
\end{tabular}

numbers is about 3hour at specification of computer with Intel core i3-2100, CPU 3.10GHz, and 4GB RAM. It takes about $20 \mathrm{sec}$ at 1 simulation number.

\section{Simulation in Korean Distribution System}

\subsection{System model and simulation conditions}

The configuration of simulated Korean distribution system model is represented in Fig. 5. The total length is $2 \mathrm{~km}$. The type of distribution line is ASCR-OC $95 \mathrm{~mm}^{2}$.

The KEPCO distribution system is a multi-grounded neutral system [21]. The neutral wire is grounded at each pole and the grounding resistance is $300 \Omega$. In addition, the KEPCO distribution system has an OHGW. The spacing between two adjacent grounds of the OHGW is $200 \mathrm{~m}$ and the grounding resistance of the $\mathrm{OHGW}$ is $50 \Omega$. Lightning arresters are installed every $500 \mathrm{~m}$ and the grounding resistance of the lightning arresters is $25 \Omega$.

This paper simulates the flashover rate by the variation of footing resistance according to the existence of OHGW. The footing resistance considered is $10,50,100$, and $300 \Omega$.

\subsection{Simulation results in case of indirect lightning}

The simulation of the flashover rate due to indirect lightning yields a value of 0 . To find the reason for this result, we analyze the overvoltage due to indirect lightning. As shown in Fig. 6, when the OHGW exists, the cases which overvoltage above $180 \mathrm{kV}$ is not occurred.

When the OHGW does not exist, as shown in Fig. 7, the overvoltage above $180 \mathrm{kV}$ is occurred when the magnitude of lightning strike is $100 \mathrm{kA}$ and the distance between lightning location and line is $110 \mathrm{~m} \sim 160 \mathrm{~m}$. 
Even though the magnitude of lightning is $100 \mathrm{kA}$, the range of distance between lightning locations and line which overvoltage above $180 \mathrm{kV}$ is occurred is narrow. The probability of lightning with $100 \mathrm{kA}$ is just $0.6 \%$ as shown in Table 1 and hence the probability of lightning with $100 \mathrm{kA}$ in distance of above discussion is very rare. Therefore, the flashover does not occur in simulation number of 1000 and if the simulation number is increased, the possibility of flashover due to indirect lightning exists.

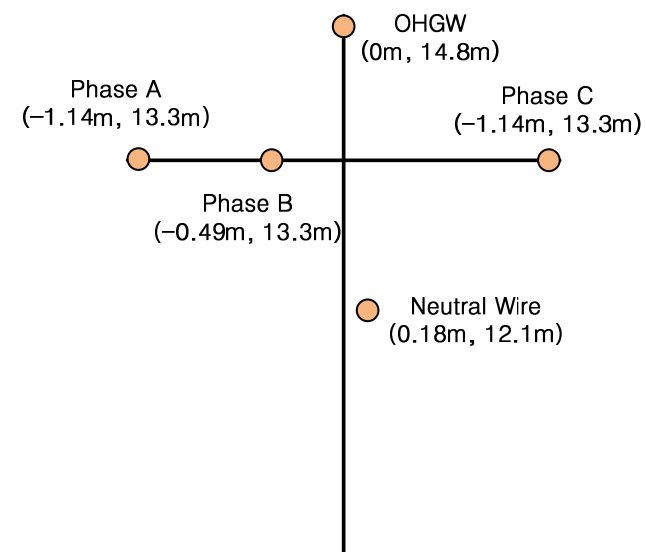

Fig. 5 Configuration of Korean distribution system

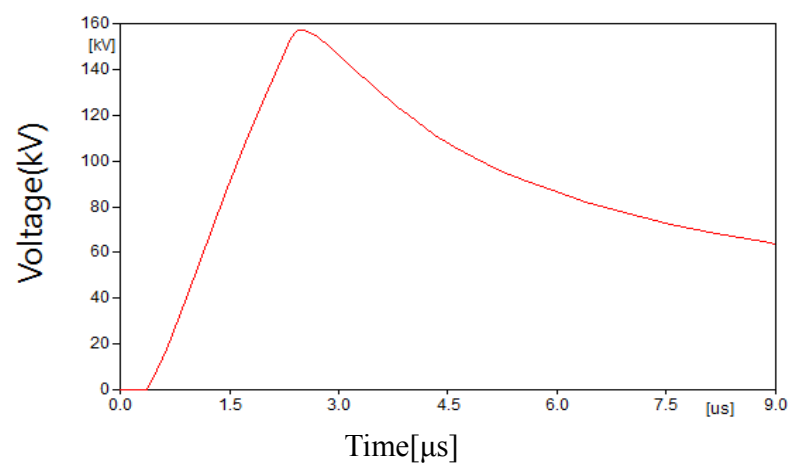

Fig. 6 Magnitude of overvoltage when the magnitude of indirect lightning is $100 \mathrm{kA}$ and $\mathrm{GW}$ exists

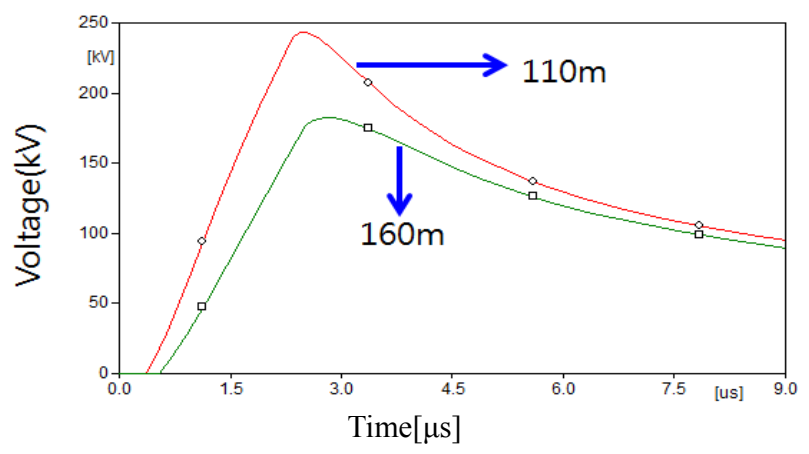

Fig. 7 Magnitude of overvoltage according to the distance between lightning location and distribution line when the magnitude of indirect lightning is $100 \mathrm{kA}$ and GW does not exist

\subsection{Simulation results in case of direct lightning}

The flashover rate due to direct lightning according to the footing resistance is shown in Table 3 . When the footing resistance is $10 \Omega, 50 \Omega$, and $100 \Omega$, the flashover rate with an OHGW is smaller than that without an OHGW. For the case where the footing resistance is $100 \Omega$ and the critical flash overvoltage (CFO) is smaller than $200 \mathrm{kV}$, the flashover rate with an $\mathrm{OHGW}$ is larger than that without an OHGW. In addition, in the case where the footing resistance is $300 \Omega$, the flashover rate with an OHGW is larger than that without an OHGW.

The reason for the obtained results is the consideration of the height of the OHGW when the striking distance and flashover rate are calculated. In Table 4, the striking distance in the case with an OHGW is longer than that without an OHGW. Hence, the probability of direct lightning in case with an OHGW is increased. In addition, for the case with an OHGW, flashover rate by direct lightning, $F_{\text {direct }}$, becomes larger. Eqs. (2) and (3) show the calculation process for the flashover rate according to the existence of an OHGW. In (2) and (3), the second term for the case with an OHGW is 14.22, while the second term for the case without an OHGW is 13.34.

Table 3 Flashover rate according to the footing resistance

\begin{tabular}{c|c|c|c|c}
\hline \multirow{2}{*}{ Footing resist. } & \multicolumn{2}{|c|}{$10 \Omega$} & \multicolumn{2}{c}{$50 \Omega$} \\
\cline { 2 - 5 } CFO $(\mathrm{kV})$ & $\begin{array}{c}\text { With } \\
\text { GW }\end{array}$ & $\begin{array}{c}\text { Without } \\
\text { GW }\end{array}$ & $\begin{array}{c}\text { With } \\
\text { GW }\end{array}$ & $\begin{array}{c}\text { Without } \\
\text { GW }\end{array}$ \\
\hline 180 & 1.9074 & 2.3463 & 2.2872 & 2.4946 \\
\hline 200 & 1.7952 & 2.3058 & 2.1216 & 2.4115 \\
\hline 220 & 1.5227 & 2.2484 & 1.6702 & 2.2927 \\
\hline 240 & 1.3463 & 2.0948 & 1.4896 & 2.1264 \\
\hline 260 & 1.1219 & 1.8612 & 1.3693 & 1.9007 \\
\hline 280 & 0.8654 & 1.6587 & 1.2489 & 1.7937 \\
\hline 300 & 0.7371 & 1.511 & 1.0232 & 1.6987 \\
\hline Footing resist. & \multicolumn{2}{|c|}{$100 \Omega$} & \multicolumn{2}{c}{300} \\
\cline { 2 - 5 } & With & Without & With & Without \\
\hline CFO(kV) & GW & GW & GW & GW \\
\hline 180 & 2.6458 & 2.558 & 2.7179 & 2.7131 \\
\hline 200 & 2.5496 & 2.543 & 2.6939 & 2.7131 \\
\hline 220 & 2.4533 & 2.4903 & 2.5977 & 2.5044 \\
\hline 240 & 2.3571 & 2.3849 & 2.5496 & 2.5044 \\
\hline 260 & 2.2128 & 2.2345 & 2.5015 & 2.5044 \\
\hline 280 & 1.9723 & 2.0614 & 2.3812 & 2.3479 \\
\hline 300 & 1.8207 & 2.0539 & 2.309 & 2.2435 \\
\hline
\end{tabular}

Table 4 Striking distance according to the existence of an OHGW

\begin{tabular}{c|c|c}
\hline \multirow{2}{*}{$\begin{array}{c}\text { Lightning } \\
\text { Current (kA) }\end{array}$} & \multicolumn{2}{|c}{ Striking distance } \\
\cline { 2 - 3 } & With OHGW (m) & Without OHGW (m) \\
\hline 4.4 & 24.68 & 24.09 \\
\hline 10 & 36.74 & 35.66 \\
\hline 20 & 50.81 & 49.34 \\
\hline 30 & 61.58 & 59.90 \\
\hline 40 & 70.77 & 68.95 \\
\hline 50 & 78.99 & 77.06 \\
\hline 100 & 112.52 & 110.29 \\
\hline
\end{tabular}


- With GW:

$$
\begin{aligned}
F_{\text {direct }} & =\frac{n_{\text {direct }}}{n_{\text {tot }}} \times N_{g}\left(\frac{28 h^{0.6}+b}{10}\right) \\
= & \frac{n_{\text {direct }}}{n_{\text {tot }}} \times N_{g}\left(\frac{28(14.8)^{0.6}+1.14}{10}\right)=\frac{n_{\text {direct }}}{n_{\text {tot }}} \times 14.22 N_{g}
\end{aligned}
$$

- Without GW:

$$
\begin{aligned}
F_{\text {direct }} & =\frac{n_{\text {direct }}}{n_{\text {tot }}} \times N_{g}\left(\frac{28 h^{0.6}+b}{10}\right) \\
& =\frac{n_{\text {direct }}}{n_{\text {tot }}} \times N_{g}\left(\frac{28(13.3)^{0.6}+1.14}{10}\right)=\frac{n_{\text {direct }}}{n_{\text {tot }}} \times 13.34 N_{g}
\end{aligned}
$$

where

$$
\begin{array}{ll}
F_{\text {direct }}: \text { flashover rate by direct lightning (flashovers / } & 100 \mathrm{~km} / \mathrm{yr}) \\
n_{\text {direct }} & : \text { number of flashover by direct lightning } \\
n_{\text {tot }} & : \text { total simulation number } \\
N_{g} & \left.: \text { ground flash density (flashes } / \mathrm{km}^{2} / \mathrm{yr}\right) \\
B & : \text { structure width }(\mathrm{m})
\end{array}
$$

To verify these results, the obtained findings were compared with the results attained with the IEEE Flash 2.0 program. IEEE Flash 2.0 estimates the lightning flashover rates of overhead electric power transmission and distribution lines according to IEEE Standards 1243 and 1410 [7-9]. The results obtained using IEEE Flash 2.0 according to the footing resistance are shown in Table 5. The inputted parameters such as the overhead distribution line, the shield wire, span, and etc. in IEEE Flash 2.0 are equal to the parameters used in the simulations. The ground flash density (GFD) is also based on the value measured by KLDNet.

The immediate comparison of values between the results of Table 5 and Table 3 is impossible because the system configuration, especially existence of lightning arrester and the cumulative probability of lightning strike considered are different. The comparison of trends is only possible between two results. When the footing resistance is larger than $100 \Omega$, the flashover rate with an OHGW is larger than that without an OHGW. Very good agreement is observed between our simulation findings and the results obtained with IEEE Flash 2.0. For reference, the value in Table 5 is larger than that in our simulation results because IEEE Flash 2.0 does not consider the existence of a lightning arrester, and the median value with $31 \mathrm{kA}$ on the

Table 5. Results using IEEE Flash 2.0 according to the footing resistance

\begin{tabular}{c|c|c}
\hline $\begin{array}{c}\text { Footing } \\
\text { resistance }\end{array}$ & $\begin{array}{c}\text { With } \mathrm{GW} \\
\text { [flashovers } / 100 \mathrm{~km} / \mathrm{yr} \text { ] }\end{array}$ & $\begin{array}{c}\text { Without } \mathrm{GW} \\
\text { [flashovers } / 100 \mathrm{~km} / \mathrm{yr} \text { ] }\end{array}$ \\
\hline $10 \Omega$ & 1.97 & 2.64 \\
\hline $50 \Omega$ & 10.48 & 10.88 \\
\hline $100 \Omega$ & 12.08 & 11.9 \\
\hline $300 \Omega$ & 13.14 & 12.49 \\
\hline
\end{tabular}

cumulative probability of a lightning strike considered by IEEE Flash 2 is larger than the value with $19.75 \mathrm{kA}$ in (1) for our simulations.

\section{Conclusions}

The previous study of flashover rate calculation is very difficult to both beginner and expert in power corporations. Therefore, this paper proposes the new and easy simulation method to calculate the flashover rate using connection of EMTP and MATLAB. The roles of EMTP and MATLAB are discussed. The proposed method is applied to the Korean distribution system. The flashover rate by direct and indirect lightning is simulated and the simulation results are discussed to verify the accurateness of proposed method. It will be possible to simulate the flashover rate at any configuration of lightning protection system using proposed method.

\section{References}

[1] Jiming Chen and Mingxiao Zhu, "Calculation of Lightning Flashover Rates of Overhead Distribution Lines Considering Direct and Indirect Strokes", IEEE Trans. on Electromagnetic Compatibility, Vol. 56, No. 3, JUNE 2014.

[2] T. Lantharthong, N. Rugthaicharoencheep, K. Supanus, and A. Phayomhom, "Effect of Waveform and Impulse Resistance on Lightning Performance in Distribution System", International Conference on Lightning Protection 2014.

[3] P. Chowdhuri, J. G. Anderson, W. A. Chisholm, T. E. Field, M. Ishii, J. A. Martinez, M. B. Marz, J. McDaniel, T. R. McDermott, A. M. Mousa,T. Narita, D. K. Nichols, and T. A. Short, "Parameters of Lightning Stroke: A Review", IEEE Trans. On Power Delivery, Vol. 20, No. 1, pp. 346-358, January 2005.

[4] Mario Paolone, Carlo Alberto Nucci, Emanuel Petrache, and Farhad Rachidi, "Mitigation of Lightning-Induced Overvoltages in Medium Voltage Distribution Lines by Means of Periodical Grounding of Shielding Wires and of Surge Arresters: Modeling and Experimental Validation", IEEE Trans. On Power Delivery, Vol. 19, No. 1, pp. 423-431, January 2004.

[5] CRIEPI, "Guide of Lightning Protection Design for Power Distribution Lines", JAPAN, 2002.

[6] H. Motoyama, Y. Kinoshita, and K. Nonaka, "Experimental study on lightning surge response of 500-kV transmission tower with overhead lines", IEEE Trans. Power Del., vol. 23, no. 4, pp. 24882495, Oct. 2008.

[7] S. Yokoyama, K. Yamamoto, and H. Kinoshita, "Analogue simulation of lightning induced voltages and its application for analysis of overhead-ground- 
wire effects," Proc. Inst. Elect. Eng., vol. 132, no. C4, pp. 208-216, 1985.

[8] Alberto Borghetti, Carlo Alberto Nucci, Mario Paolone, "An Improved Procedure for the Assessment of Overhead Line Indirect Lightning Performance and Its Comparison with the IEEE Std. 1410 Method", IEEE Transactions on Power Delivery, Vol. 22, No. 1, pp. 684-692, January 2007.

[9] "Guide for improving the lightning performance of electric power overhead distribution lines", IEEE Std 1410, 2010, IEEEWorking Group on the lightning performance of distribution lines.

[10] "IEEE Guide for improving the lightning performance of transmission lines", IEEE Std. 1243, 1997, Working Group on Estimating the Lightning-Performance of Overhead Transmission Lines.

[11] http://www.sourceforge.net/projects/ieeeflash

[12] http://kldnet.kepri.re.kr

[13] F. Heidler, J. M. Cvetic, and B. V. Stantic, "Calculation of lightning current parameters", IEEE Trans. Power Del., vol. 14, no. 2, pp. 399-404, Apr. 1999.

[14] Chul-Hwan Kim, Myung-Hee Lee, Raj K. Aggarwal, "Educational Use of EMTP MODELS for the Study of a Distance Relaying Algorithm for Protecting Transmission Lines", IEEE Transactions on Power Systems, Vol. 15, No. 1, pp. 9-15, February 2000.

[15] Sang-Min Yeo, Chul-Hwan Kim, "Analysis of Transient Overvoltage within $345 \mathrm{kV}$ Korean Thermal Plant", Journal of Electrical Engineering \& Technology, Vol. 7, No. 3, pp. 297-303, 2012.

[16] Chul-Won Park, Dong-Kwang Shin, Chul-Hwan Kim, Hak-Man Kim, Yoon-Sang Kim, "Study on Advanced Frequency Estimation Technique using Gain Compensation", Journal of Electrical Engineering \& Technology, Vol. 6, No.4, pp. 439-445, 2011.

[17] Hans Kristian Hoidalen, "Analytical Formulation of Lightning-Induced Voltages on Multiconductor Overhead Lines Above Lossy Ground", IEEE Transactions on Electromagnetic Compatibility, Vol. 45, No. 1, pp. 92-100, February 2003.

[18] Alexandre Piantini, Jorge M. Janiszewski, "LightningInduced Voltages on Overhead Lines - Application of the Extended Rusck Model", IEEE Transactions on Electromagnetic Compatibility, Vol. 52, No. 3, pp. 548-558, August 2009.

[19] F. Rachidi, C. A. Nucci, and M. Ianoz, "Transient analysis of multiconductor lines above a lossy ground," IEEE Trans. on Power Delivery, vol. 14, no. 1, pp. 294-302, Jan. 1999.

[20] M. Rubinstein, "An approximate formula for the calculation of the horizontal electric field from lightning at close, intermediate, and long range," IEEE Trans. Electromagn. Compat., vol. 38, pp. 531535, Aug. 1996.

[21] Keon-Woo Park, Hun-Chul Seo, Chul-Hwan Kim, Chang-Soo Jung, Yeon-Pyo Yoo, Yong-Hoon Lim,
"Analysis of the Neutral Current for Two-Step-Type Poles in Distribution Lines", IEEE Transactions on Power Delivery, Vol. 24, No. 3, pp. 1483-1489, July 2009.

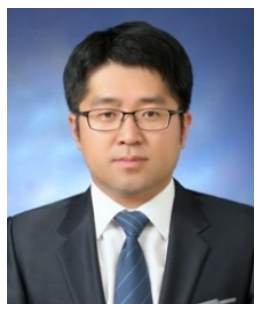

Hun-Chul Seo He received his B.S, M.S, and Ph. D. degrees from Sungkyunkwan University, Korea, 2004, 2006, and 2013, respectively. He worked for Korea Electrical Engineering \& Science Institute, Seoul, Korea, as a researcher in power system division from 2006 to 2009. He was a postdoctoral fellow in the dept. of electrical engineering, Yeungnam University, Korea, from Sep. 2013 to Jan. 2014. From Mar. 2014, he is an assistant professor with the School of IT Engineering at Yonam Institute of Digital Technology, Korea. His research interests include power system transients, protection and stability.

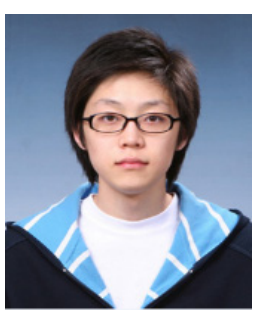

Joon Han He received his B.S degree in School of Electrical Engineering from Soonchunhyang University, Korea, 2011 and M.S degree in College of Information and Communication Engineering from Sungkyunkwan University, Korea, 2013. At present, he is working on his $\mathrm{Ph}$. D thesis at Sungkyunkwan University. His research interests include power system transients, protection and DC distribution system.

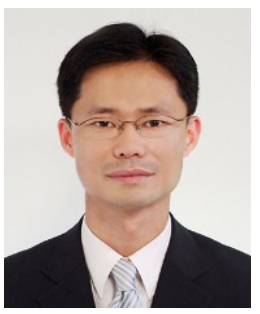

Sun-Kyu Choi He received his B.S and M.S degrees in School of Electrical Engineering from Korea University, Korea, 2000 and 2002. He has been with KEPRI, KEPCO, as a member of the researcher since 2003. His special fields of interest are a grounding method, lightning protection and power quality of distribution system.

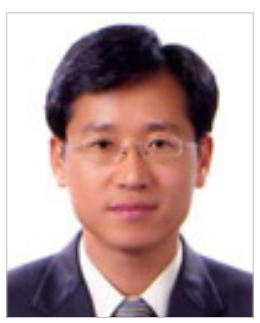

Byung-Sung Lee He received his Ph.D from Chungnam National University in 2006 in high voltage Engineering. He has been with KEPRI, KEPCO, as a member of the researcher since 1995. His special fields of interest are the intelligent distribution automation system, RCM of distribution facilities and lightning protection, and the lifetime estimation of distribution equipments. 


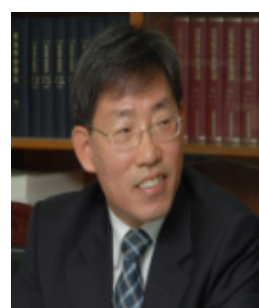

Chul-Hwan Kim In 1990 he joined Cheju National University, Cheju, Korea, as a full-time Lecturer. He has been a visiting academic at the University of BATH, UK, in 1996, 1998, and 1999. Since March 1992, he has been a professor in the School of Electrical and Computer Engineering, Sungkyunkwan University, Korea. His research interests include power system protection, artificial intelligence application for protection and control, the modelling/protection of underground cable and EMTP software. He received his B.S and M.S degrees in Electrical Engineering from Sungkyunkwan University, Korea, 1982 and 1984, respectively. $\mathrm{He}$ received a Ph.D in Electrical Engineering from Sungkyunkwan University in 1990. Currently, he is a director of Center for Power IT(CPIT) in Sungkyunkwan University. 